REPORT

\section{The governance of big}

\section{transformations}

\author{
Miranda Schreurs, Professor of Environment and Climate Policy, \\ School of Governance, Technical University of Munich, \\ Richard Wagner Straße 1, 80333 Munich (Miranda.Schreurs@hfp.tum.de), \\ (D) orcid.org/0000-0002-6617-4906 \\ Stefan Wurster, Professor of Policy Analysis, School of Governance, \\ Technical University of Munich (Stefan.Wurster@hfp.tum.de), \\ (D) orcid.org/0000-0003-2532-0249
}

On 21-23 March 2019, the School of Governance, Technical University of Munich hosted the annual conference of the comparative politics section of the German Association for Political Science (Deutsche Vereinigung für Politikwissenschaft). The theme of the conference was the governance of big transformations and was organized in collaboration with several of the association's standing groups: Democracy and Comparative Dictatorships and Extremism; and thematic networks: Energy Transformation and Internet and Politics.

The idea of hosting this conference was made in part to respond to the organizers' belief that the political science discipline needs to engage more directly and deeply with the opportunities but also the governance challenges associated with big technological, scientific, and environmental transformations. Examples of big transformative developments include fundamental technological changes, such as big data, autonomous vehicles, robotics, the Internet of Things, social media, artificial intelligence, and genetically modified organisms. They also include major threats to ecological systems, such as climate change, biodiversity loss, plastic in the oceans, and chemical pollution. Coinciding with these technical and environmental transformations, there are major shifts occurring in political systems, including the rise of far right parties and a drift towards authoritarianism in various countries. The main objective of the conference was to examine the emergence, development, inter-relationships, and political meaning of these big transformative processes. The large number of participants (more than 150) shows that these themes are resonating in the political science discipline.

This is an article distributed under the terms of the Creative Commons Attribution License CCBY 4.0 (https://creativecommons.org/licenses/by/4.0/)

https://doi.org/10.14512/tatup.28.2.s69

\section{Big transformations in the plural}

There are many big and dramatic transitions underway. Big data and artificial intelligence are transforming the speed and volume with which information can be collected and used. This opens exciting possibilities for enhancing our scientific understanding of all kinds of problems. Big data and artificial intelligence will help to revolutionize medicine, agriculture, transportation systems, and energy structures. Large quantities of data can be gathered and analyzed almost instantly. At the same time, the ongoing revolution in communication technologies raises important privacy issues. The ease with which data can now be collected, stored, and altered raises many concerns about how this data may be used. Fake news, international interference in democratic elections through social media, and the idea that "Big Brother" is watching you, have raised concerns in the discipline.

Some of the transformations, like climate change and biodiversity loss, are taking place over longer periods of time and will require both major changes to existing structures and practices and long-term political commitment. Others are more disruptive, like big data and artificial intelligence, and will require rapid governance responses. Some are region-specific while others will have a global reach. Often the changes involve great uncertainty and high levels of complexity.

Big transformations raise important governance challenges. While they hold promise for contributing and even solving some long-standing problems, they may also have unintended social, environmental, and health consequences. They may lead to new discoveries but can also invite public protest or even threaten the survival of political systems. In order to keep pace with these fast-moving and highly complex changes, policymakers are being pushed to develop more reflective forms of governance that promote policy learning and adaptation. New forms of more participatory governance strategies (e.g. citizen initiatives, multi-stakeholder commissions), innovative policy instruments (e.g. sunset legislation, auctioning), and approaches to political participation (e. g. term limits, online petitions, ombudsperson for future generations) are being tried out. At the same time, these trends have pushed some governments towards greater nationalism, protectionism, and a retreat from global institutions and norms.

From the perspective of Comparative Politics this raises important questions of high theoretical as well as practical relevance. How can comparative politics best contribute to the study of big transformations in meaningful ways? Even though many of these transformations will affect all countries, it is already evident that effects and reactions differ tremendously by issue, level of government, or political system. Comparative analysis across national borders is therefore a necessary and timely task.

\section{Panel themes}

The conference brought together scholars with an interest in examining these fundamental questions of big transformative changes. Conference participants examined how different political systems are adapting politically, economically and socially to these changes or are themselves working to promote or trig- 
ger (deep) change. They addressed the impacts observed in relation to specific sectors, policy areas, and societal and policy processes from a national, comparative or international perspective.

The panel themes are revealing of the issues that are grasping the attention of political scientists. There was a panel dealing with the governance of cybersecurity. Security studies are being faced with new concerns: computer hacking, internet attacks of key infrastructures (e.g. nuclear power plants, dams), and drone use in warfare and terrorism. The definition of what is meant by a threat and how governments and industry may need to respond are changing. The papers of this panel focused on different aspects in the field of cybersecurity: technical and organizational measures for network and information security protection, and gies, criticizing their effect on national budgets or rejecting international policy approaches. On the other hand, fundamental technological changes have made it much easier and cheaper for populist challengers to communicate with specific audiences and to make their positions seem more accepted and widespread. Catch-all parties thrived as a result of the spread of TV; Twitter gives populist parties a mighty instrument to build-up a substantial following.

Ethical concerns are being raised by various technological developments. With the emergence of new technologies we see decline, decay or even retreat of traditional political and technological structures. They are reaching deeply down into the cultures and ways of life of different social groups and individu-

\section{To date, there has been only limited study of populists' relationship with and effects on big transformations.}

debates about reforming law enforcement, signal intelligence and cyber defense. The panel also included a comparative perspective, focusing on different approaches and performances by democracies and autocracies.

Other panels examined interrelationships between different kinds of transformations. The transformations of infrastructures and digitalization are closely intertwined. Digitalization is influencing major transformative processes, such as the energy transition, regional and urban development, and the construction of large-scale infrastructure projects. The new forms of collective problem solving and cooperation made possible through internet communication are altering how democracy functions. It also is inviting new forms of dialogue as the internet becomes a virtual organization of political, business, and civil society actors. These changes were the subject of a panel addressing new forms of political participation and their impacts on organizations.

Other panels dealt with the governance of the transformation of the transport system (Verkehrswende). With growing pressure on the transport sector to address its greenhouse gas emissions, there is rising interest in electric mobility as well as in the promotion of alternative forms of transportation (and especially public transportation and bicycles). In addition, there are new technological possibilities made available through autonomous driving vehicles with other technologies on the horizon, e. g. the Hyperloop. These trends raise many important governance and ethical questions that were enthusiastically debated.

Conference panelists further considered challenges to democratic structures and signs of a resurgence of authoritarianism. There are clashes between those supporting and those opposing globalization and the structures which underpin it. To date, there has been only limited study of populists' relationship with and effects on other big transformations. On the one hand, populist political forces may mobilize resistance towards policy changes in areas such as climate change mitigation or renewable ener- als. Some panelists noted the resurgence of religion in politics, a possible reaction to the major technological changes underway. Debates about euthanasia, designer babies, circumcision, migration, and the placing of religious symbols in public places are bringing religion back into politics in sometimes divisive or polarizing ways.

Three keynote speeches served as conference highlights. Former UNEP Director and Environment Minister Klaus Töpfer gave a speech on "The Governance of Big Transformations in the Anthropocene," noting that human activities are so fundamentally transforming our planet that major rethinking of governance systems is required. Dirk Messner, newly appointed Director of the United Nations University, Institute for Human and Environmental Security, Bonn spoke about the major challenges associated with climate change and sustainability issues, but also the many possibilities that can come from tackling these issues. Finally, Uwe Schneidewind, President of the Wuppertal Institute for Climate, Environment and Energy, discussed what needs to be done to ensure a safe operating space for humans in a planet that is rapidly being transformed by climate change, acidification of the oceans, and biodiversity loss. He called for new welfare models and an efficiency revolution.

\section{Further Information}

Information on all panels and panelists via the conference website: http://www.bigtransformations.hfp.tum.de/ 